\title{
Functional effect of transient transurethral catheterization on micturition in women: comment
}

\author{
Françoise A. Valentini • Pierre P. Nelson
}

Published online: 15 November 2012

(C) The International Urogynecological Association 2012

\section{Dear Editor,}

We would like to congratulate Suskind and Smith on their article on "Evidence of a Functional Effect of Transient Transurethral Catheterization on Micturition in Women," and we agree with their conclusion, from the only analysis of urodynamic parameters of free uroflow, of the functional effect of transient transurethral catheterization on micturition in women [1].

Our main concern is that results are only based on change in uroflow curve pattern and of $\mathrm{Q}_{\mathrm{ave}}$ value. If the geometric obstructive effect of an in situ catheter is not arguable because of a reduced cross section of the flow, the persistent residual obstructive effect on a free flow, after the catheter has been removed, has been little studied. We think that we can offer some arguments. In a preliminary study [2], we analyzed the effect of a urethral catheter during intubated flow that followed a free uroflow, and we proposed the occurrence of a compression-like effect of the urethra; this would explain a greater decrease in $\mathrm{Q}_{\max }$ than expected by the geometric effect of the catheter.

More recently [3], using the value-belief-norm (VBN) model for a careful analysis of tracings, we concluded that the cause of this additional effect (observed in $62 \%$ of our population-positive group) was a residual excitation of the sphincter. In addition, the phenomenon (observed during intubated flow) could remain the same (condition observed in $31 \%$ of the positive group) during free uroflow after catheter removal.

Thus, as the authors concluded, the transient catheterization has a more complex impact than expected.

\section{References}

1. Suskind AM, Smith PP (2012) Evidence of a functional effect of transient transurethral catheterization on micturition in women. Int Urogynecol J 23:1245-1248. doi:10.1007/s00192-011-1646-2

2. Valentini FA, Marti BG, Robain G, Nelson PP (2008) Differences between the data from free flow and intubated flow in women with urinary incontinence. What do they mean? Neurourol Urodyn 27:297-300

3. Valentini FA, Robain G, Hennebell DS, Nelson PP (2012) Decreased maximum flow rate during intubated flow is not only due to urethral catheter in situ. Int Urogynecology J. doi:10.1007/ s00192-012-1856-2
A reply to this comment is available at doi 10.1007/s00134-012-1975-9.

F. A. Valentini $(\bowtie) \cdot$ P. P. Nelson

ER6 - Université Pierre et Marie Curie (Paris 06) - Physical

Medicine and Rehabilitation Department, Hôpital Rothschild,

5 , rue Santerre,

75012 Paris, France

e-mail: francoise.valentini@rth.aphp.fr

P. P. Nelson

e-mail: favalentini@gmail.com 